\title{
Erratum to: Crystallization in Microgravity and the Atomic-Resolution Structure of Uridine Phosphorylase from Vibrio cholerae
}

\author{
P. A. Eistrikh-Heller ${ }^{a}$, S. V. Rubinsky ${ }^{a}$, V. R. Samygina ${ }^{a, b}$, A. G. Gabdulkhakov ${ }^{a}$, M. V. Kovalchuk ${ }^{a, b}$, \\ A. S. Mironov ${ }^{c}$, and A. A. Lashkov"* \\ ${ }^{a}$ Shubnikov Institute of Crystallography of Federal Scientific Research Centre "Crystallography and Photonics," \\ Russian Academy of Sciences, Moscow, 119333 Russia \\ ${ }^{b}$ National Research Center "Kurchatov Institute," Moscow, 117545 Russia \\ ${ }^{c}$ Engelhardt Institute of Molecular Biology, Russian Academy of Sciences, Moscow, 119991 Russia \\ *e-mail:alashkov83@gmail.com \\ Received November 8, 2021; revised November 8, 2021; accepted November 8, 2021
}

DOI: $10.1134 / \mathrm{S} 1063774521070270$

The article "Crystallization in Microgravity and the Atomic-Resolution Structure of Uridine Phosphorylase from Vibrio cholerae", written by P.A. Eistrikh-Heller, S.V. Rubinsky, V.R. Samygina, A.G. Gabdulkhakov, M.V. Kovalchuk, A.S. Mironov, and A.A. Lashkov, was originally published electronically in Springer-Link on 05 October 2021 without Open Access. After publication in volume 66, issue 5, pages 777-785 the authors decided to make the article an Open Access publication. Therefore, the copyright of the article has been changed to (C) The Author(s) 2021 and the article is forthwith distributed under the terms of a Creative Commons Attribution 4.0 International License (http://creativecommons.org/licenses/by/4.0/, CC BY), which permits use, duplication, adaptation, distribution and reproduction of a work in any medium or format, as long as you cite the original author(s) and publication source, provide a link to the Creative Commons license, and indicate if changes were made.

The original article can be found online at https://doi.org/10.1134/S1063774521050059 